\title{
ACTION RESEARCH - APPROACH FOCUSED ON THE DEVELOPMENT OF EDUCATIONAL PRACTICE
}

\author{
Maja Domazet ${ }^{1}$, \& Siniša Opić ${ }^{2}$ \\ ${ }^{1}$ Kindergarten Maslačak, Zaprešić (Croatia) \\ ${ }^{2}$ Faculty of Teacher Education - University of Zagreb (Croatia)
}

\begin{abstract}
The aim of the paper is to introduce a different approaching perspective of the children with internalizing behaviors using the implemented action research. In fact, this action research is a tool for approaching to the study of the internalizing behavioral problems. Practitioners and other participants of the research can awake their own practice and thus start some changes and improvements while using it. Considering the fact that in the literature are not many described models of prevention, support and action targeted to these behaviors, especially in the facilities of early and preschool education, the approach using action research has been imposed as the most appropriate. It is the most suitable for working with children who do not manage to create social opportunities by themselves nor develop their social and emotional skills and resistance. The largest part of this research is referred to direct interaction of children identified as reclusive, shy and fearful. Specific workshops and targeted activities contributed to a significant change in children's social skills. This research will result in strong awareness of educators, expert teams, principle and parents for the necessity of the children. A different organization of educators' working hours will influence the quality of support which has proven to be an irreplaceable reliance of safety, so it is important that it is available to children even after structured working hours. Hence, the principle introduces a special professional training and different structure of working hours in order to keep the quality of support reached through this research.
\end{abstract}

Keywords: Internalizing behaviors, action research, action research outcomes.

\section{Introduction}

Action research is the basic strategy of professional growth which is an individual or a group examination of proper professional practice with the purpose of self-advancement. This self-advancement will influence the methods of the better quality aimed towards children. In action research practitioners upgrade their own practice in direct surroundings. The researcher begins the study by questioning his own practice and attempting to recognize the areas he can change and improve using his inner reflection (Markowitz, 2011). Thus, a reflexive practice becomes a starting point for changes. The author Fullan uses the term educational changes whose aim is to influence a pupil positively (child). However, during this process of changes, the emphasis is given to professional development (Fullan, 1993, 1999: according to Slunjski 2016). Bognar (2006) quotes that teachers/educators cannot only be the users of research implemented by someone from the outside. By accepting the active role in the schools' research, teachers become the reflexive practitioners (Schoen, 1984; according to Bognar 2006), teachers' researchers or action researchers (McNiff 2002; according to Bognar (2006). Accordingly, educators from the facilities of early and preschool education have been observed. Slunjski (2016) quotes that action research is very effective form of sustained professional development of preschool teachers aimed towards consolidation of collaborative modalities of their educational reflection and impact. The author Miljak (2015) assumes that the educational practice is still much unexplored and it will never be fully explored because it is the area of continuous worry for further, deeper and better researches and improvements. When we go one step further in the research of practice, our horizons start changing. Exactly here the educators become the main bearers of the research and changes. Thus, action research is valuable tool, not just as for making changes, but also as the tool of studying and constant questioning and exploring. "Action research is form of collective self-reflected studying implemented by participants in the social situations in order to improve rationality and justice of own social or educational practices, as well as understanding of these practices and situations in which they are conducted. This approach is action research only when it is cooperative, although it is important to understand that action research of the group is implemented 
throughout the critically questioned impact of particular members of the group "(Kemmis \& McTaggart 1988; according to Cohen, Manion, Morrison 2007; 227). Action research enable that participants can get a feedback in the specific condition of their professional development and accordingly, correct their actions in order to achieve desired changes (Bognar, 2001). In that way action research is valuable for all participants, both for groups and individual because action that is the subject of research brings to improvement or changes of the group and individual and their impacts. It is important to emphasize that action research imply active participation of all interested participants, so they are not implemented on people but with people (Reason, 1994; according to Bognar 2001).

Some of the authors revolve the objectivity that can appear as a problem in the implementation of action research (Grounlund, 1981; Stinger, 1996; Sekulić-Majurec, 2007; Zuber-Skerritt,1996; Winter, 1982), but Kemmis, McTaggert and Nixon (2014) think that people inside the research have the particular advantages such as the fact that only the participants can precisely see and understand their actions and thus awake the change as well as the consequence of their behaviors and actions. Also, through the report of the implemented action research it is attempted to represent the effort of researchers and practitioners in the change of their own practice and educational actions, dilemmas and reflections they had. The directed action as a result of reflexive practice is represented. Even though the particular changes have not been managed, it is important that a process of learning has been noticed during this process, which is the aim of action research.

\section{The start of research}

Above mentioned action research has been implemented in the kindergarten during one pedagogical year. The kindergarten consisted of 25 groups with two preschool teachers (educators) in each group. The initiator of the action research is the preschool teacher who has three children with internalizing behaviors in the group. It has been noticed that a small amount of time has been dedicated to those children, not only within the group, but also in the kindergarten generally which is clearly seen later from the curriculum of the facility as well as from the educator's surveys. It is probably because children with these behaviors are invisible and non-demanding and do not attract any attention, so the educators turn to more difficult and demanding situations. The analysis of the curriculum of the facility in the last five years, has given a clear insight into no existing planned support for these children, although the educators mentioned internalizing behaviors as very concerning through a few reports on the curriculum. Also, the surveys completed by educators, were used as the tool for analysis of the initial situation. The analysis of the survey implemented among the educators of nineteen groups on the sample of 369 children aged 3-7, shows a particular frequency of characteristic behaviors. For instance, from the total number of surveyed children, the educators estimate that $11,11 \%$ of them often play alone or $13,27 \%$ of them never initiate a play, $6,23 \%$ separate from other children, $6,77 \%$ observe the play but do not participate or $4,06 \%$ of them do not ask for help when needed. This is one part of the characteristic behaviors observed by educators, but their numbers are alarming. The educators mention some other behaviors they notice: biting nails, quiet moaning, hidden delight, passive observing, avoiding eye contact, looking for their educator, choosing uncrowded places, avoiding noise, noisy or dynamic games, verbal aggression, obtrusion, like when being encouraged by the child they trust to. The imposing problem for educators is: "yes, the problem exists; the children with internalizing behaviors exist in every group, but what to do with them? How to help them? How far to be involved? Will our intervention help them? How to react? How to be sure in intervention? Those questions have led to approach to this problem throughout action research that includes observation the children and action in the practice.

It has been demanded from the researchers to estimate their own methods aimed towards these children and to inspect whether they have been useful or not. For instance, anxiety, occurring in the pre-school period, is not disturbing for the surrounding, but if the adults do not pay attention and just leave it to develop, it can be a trigger for emotional problems. It is similar with the restraint which is most often a reflection of not being confident into yourself and others and can lead to social incompetence which results in uncomfortable emotional conditions (Đuranović \& Opić, 2013). Moreover, a necessity of dedicating to this problem has been noticed because the number of children mentioned by the educators in this context is not individual, but there really exist a great number of children who need the attention of adults. Therefore, some research questions have been asked: How to response to silent needs and requests of children with internalizing behaviors? How to give a support to a child and follow his needs, possibilities and interests? 


\subsection{Internalizing behaviors}

The starting point of the further research was the examination of literature and theory that embrace those behaviors in order to understand the characteristics and needs of children. The classification on internalizing and externalizing disorders quotes Brajša Žganec (2003). The author claims that internalizing disorders refer to overreacted controlled behaviors, depressive behaviors, somatic changes and reclusiveness. According to Bouillet and Uzelac (2007), disorders are divided into externalizing or mostly active behavioral disorders, and they refer to not enough controlled behaviors (obtrusion, lying, aggression, destruction, opposing, defiance), while internalizing or mostly passive disorders refer to overreacted behavioral control aimed towards yourself (fear, carelessness, reclusiveness). This division does not classify or determine an exact division, but it is only an orientation classification. In internalizing behaviors, the child creates a problem only for himself while in the externalizing, he creates a problem for the surrounding. This kind of behavior does not attract a huge attention, so those difficulties are usually discovered later. According to Lebendina Manzoni (2007), the children of this behavior show fear, tense, shyness, anxiety and sadness. Hence into the group of those behaviors also belong fears in childhood, social reclusiveness and depression. The same author explains that social reclusiveness is mainly based on concern what others think about us. So, the work targeted on children should be based on reinforcement of "self" as well as the attempt of changing the negative way of thinking and experience acquisition which will change the negative schemes the child possesses. Katz and McClallen (1999) quote reclusiveness and shyness as the risky factors and behaviors that should not be ignored. Shyness is according to them, a certain dose of child's reticence, which is a sign that he is aware of unknown situation and its participants, but this shyness cannot be overcome during the childhood. This dose of shyness, according to the same authors, it a result of the fact that children do not possess enough of knowledge, skills or understanding necessary to enter the pleasant relationships. A reclusive child is mostly quiet, calm, alone, daydreaming, timid, unsecure, speaks little, quietly or whispers, stutters, has difficulties with interaction, doesn't have permanent friends, chooses a company of much older or younger, avoids new and unknown situations, is shy, complains about physical difficulties, is slow in most of social contacts, does not like speaking aloud and in front of the others, sits absently and thoughtfully, needs a little for himself, emotional reactions are mild and sometimes barely noticeable. A deficit in social relationships and subjective reaction on that deficit result in emotional experience named loneliness (Klarin, 2002). Lebedina Manzoni (2007) claims that the best treatment for reclusiveness is learning the positive model of behavior, acquiring the positive experiences in social contacts and learning social skills in interaction with others. The child like that requires attention and feeling of love, encouragement to start communicating, activity he likes in order to gain faith in his abilities. In other words, it is necessary to release him of this isolation to participate in a free and spontaneous communication (Čuturić,1995). From the assessment of initial condition and from these scientific conclusions a need for working with those children has been imposed and action research enables the critical thinking and improvement of educational practice.

\section{Implemented action research}

After procedures including gathering of participants, initial problem identifying, researching and finding the answers from the literature, some particular postulates, aims and initial tasks have been determined and will eventually be modified after recruitment. A team consisting of 9 educators (preschool teachers) has been defined. The first focus group has been arranged and some theoretical basis for discussing this issue as well as the educators' motivation has been considered. From discussion of educators, it can be concluded that educators have awaken the problem but are insecure in actions they can do. They do not doubt to support children. Also, working within small groups has been suggested. A table for monitoring behavior of children has been formed and participants can write direct perceptions from the practice to share them with the group at the next meeting. The questions that have been considered and discussed about on the focus group are a kind of guidance for monitoring children in everyday environment. From educators' perceptions, behaviors mentioned in the literature can be confirmed. Those children are insecure, calm, quiet, lonely, have difficulties with interaction, need to be encouraged by educators and like quiet games. From all these examples it can be noticed that children need educators' help, so a discussion on suggested workshops organized by educators included into the research has been initiated. The workshops would be integrated into scheduled curriculum and the emphasis is put on the work in small groups and calm atmosphere. The children with internalizing behaviors estimated by educators would be included into the workshops, but only with the consent of a child and parents. The children have a right to choose whether to participate or not. Other children from the group also can participate, but the workshop manager must beware a calm atmosphere and that the groups are less than those in which children usually stay. From the previous mentioned survey for 
educators, a special interest of those children is clearly seen which could be used as stimulus on activities at workshops. Educators of nineteen groups estimated that children have the biggest interests for art and calm activities. This fact also matches with literature. Expressive techniques, such as drawings, molding, help reclusive children to say something about themselves with no force. With the help of expressive techniques, a child will relax and encourage himself (Čuturić, 1995). Throughout the survey some methods of educators are visible and it shows how they encourage activating children they consider having internalizing behaviors. The answers show that educators' intervention is inevitable. Some specific behaviors of children have been analyzed as well as the proposals of action. Considering the estimation that those children like to work in smaller groups or individual approach, the suggestion is to implement workshops with them in order to express themselves through planned and creative activities, especially on social plan. Twelve children aged 5-7 years have been included into the workshop and 19 workshops have been organized in total. Before children's inclusion, parents who supported the idea were consulted. Discussions with parents show that they are very aware of the behavior of their child and are mostly concerned. The conclusion of the second focus group is starting the workshops. Also, the principle has supported workshops and continuance of research. In the next focus group, the workshops that encourage interaction within small groups through the art and other creative activities will be analyzed. Every workshop is planned to have a topic, aim, chosen task and finally should be documented and estimated. In the analysis of workshops, a special emphasis is given to children and their reactions. Thus, the estimations of the workshops are very important because they transfer important information about child and the according to their results the next workshop is planned. Every new workshop has introduced activities that include more cooperation and communication among children. Information and conclusions of each workshop have been discussed at participants' meetings. What is more, each activity of the child has been documented and those recordings have been of a great importance for reflection and further planning. The behaviors and reactions of both children and educators have been analyzed. Self-reflections of educators who critically explained their actions and their influence on children are very important. After analyzing and implementation of the workshops, reconsideration of research questions is analyzed. In fact, particular assumptions have been concluded, for instance, by reflections and different approaches it can be answered to children's demands although those kinds of approaches are not usual (workshop organization, for example). Furthermore, by gradual and mindful procedures, educator does not change a child, but helps him to develop new skills in appropriate way. New research questions have been imposed through reflections: How to raise a support quality? How to transfer the behaviors developed at workshops to the group? Answers on these questions have happened at the fourth focus group which was the analysis of the influence of the research on children's behaviors. A detail effect of workshops on every child, the methods children used to change their behaviors and the procedures of educators have been commented. A comparison of behaviors before and after workshops has been done. This moment is very important because it discovers the level of usefulness of the procedures and actions made by the research. It also discovers how this type of support helps a particular child.

\section{Results of action research}

Comparison and analysis of children's behaviors before and after workshops' implementations have given excellent results. Educators and parents estimated that children are more open-minded, less shy, verbalize their needs more easily, are more confident towards other children, communicate with other children within regular group, firstly with the friends from workshops and then with other children, do not need the constant presence of educator, leave their parent more easily. There is a drastic change visible in one boy's behavior. He started speaking aloud at the workshops and he did not do it before. There are no changes in the behaviors of two children, but they express their will to participate at the workshops. The greatest contribution is awareness of teachers and co-experts about importance of dealing with this issue. A planned support of those children has been put in the next curriculum of the facility. According to the clear evidence that this program of support helps children, the principle has adjusted and reacted on their needs. It means that she has flexibly approached to the organization of working hours of educators in order to continue with the support program. So, she adjusted the children's and educators' timetables in order to accept children's needs. Also, she enabled professional development of interest, not the linear one. The educators who develop support to children with internalizing behaviors are given a great chance to direct their education exactly where necessary including the flexible organization of working hours. 


\section{References}

Bognar, B. (2001). A critical-emancipatory approach to action research. Life and school: a journal for the theory and practice of education, 47 (2001), 6. 45-60. Retrieved from https://www.bib.irb.hr/679320

Bognar, B. (2006). Action research in school. Educational sciences, 8 (1 (11)), 209-228. Retrieved July 16,.2020, from: https://hrcak.srce.hr/26189

Bouillet, D., \& Uzelac S. (2007). Fundamentals of social pedagogy. Zagreb: Školska knjiga.

Brajša-Žganec, A. (2003). Child and family: emotional and social development. Jastrebarsko: Naklada Slap.

Cohen, L., Manion, L. \& Morrison, K. (2007). Research Methods in Education. Jastrebarsko: Naklada Slap.

Čuturić, N. (1995). My child worries me. Zagreb: Školska knjiga.

Đuranović, M., \& Opić, V. (2013). Possibilities of preventing of risky behaviors of preschool children. Magistra Iadertina, 8. (1.), 101-111. Retrieved June 9, 2020, from: https://hrcak.srce.hr/122644

Katz, L. G., \& McClellan, D. E. (1999). Fostering children is social competence: The teacher's role. Zagreb: Educa.

Kemmis, S., McTaggart, R. \& Nixon, R. (2014). The Action Research Planner Doing Critical Participatory Action Research. eBook. Singapore: Springer Science+Business Media.

Klarin, M. (2002). The feeling of loneliness and social behaviour of school children in the context of social interaction. Annual of Social work, 9 (2), 249-258. Retrieved July 20.7, 2020, from: https://hrcak.srce.hr/3523

Lebedina-Manzoni, M. (2007). Psychological basics of behavior disorders. Jastrebarsko: Naklada Slap.

Markowitz, A. (2011). Teachers action research in teaching: different view. In D. Kovačević, R. Ozorlić-Dominić (Eds.), Action Research for the Professional Development of Teachers. (11-26). Zagreb: Education and Teacher Training Agency.

Miljak, A. (2015). Early Childhood Development Curriculum: Model Source II: A Handbook for Educators and the Professional Team in Kindergartens. Zagreb: Mali professor.

Slunjski, E. (2016). Outside of the frame 2: Change. From a competent individual and institution to a competent learning community. Zagreb: Element. 